University of South Carolina

Scholar Commons

$5-2008$

\title{
Race Differences in Activity, Fitness, and BMI in Female Eighth Graders Categorized by Sports Participation Status
}

John R. Sirard

Karin A. Pfeiffer

Marsha Dowda

University of South Carolina - Columbia, mdowda@mailbox.sc.edu

Russell R. Pate

University of South Carolina - Columbia, rpate@mailbox.sc.edu

Follow this and additional works at: https://scholarcommons.sc.edu/

sph_physical_activity_public_health_facpub

Part of the Public Health Commons

Publication Info

Published in Pediatric Exercise Science, Volume 20, Issue 2, 2008, pages 198-210.

Sirard, J. R., Pfeiffer, K. A., Dowda, M., \& Pate, R. R. (2008). Race differences in activity, fitness, and BMI in female eighth graders categorized by sports participation status. Pediatric Exercise Science, 20(2),

198-210.

(C) Pediatric Exercise Science, 2008, Human Kinetics

This Article is brought to you by the Physical Activity and Public Health at Scholar Commons. It has been accepted for inclusion in Faculty Publications by an authorized administrator of Scholar Commons. For more information, please contact digres@mailbox.sc.edu. 


\title{
Race Differences in Activity, Fitness, and BMI in Female Eighth Graders Categorized by Sports Participation Status
}

\author{
John R. Sirard, Karin A. Pfeiffer, Marsha Dowda, and \\ Russell R. Pate
}

\begin{abstract}
The purpose of this study was to identify racial differences in physical activity (PA), fitness, and BMI in female 8th-grade sports participants and nonparticipants. Girls from 31 South Carolina middle schools $(N=1,903,48 \%$ White; mean age $=$ $13.6 \pm 0.63$ ) reported PA and previous year sports-team participation, completed a submaximal fitness test, and had height and weight measured. Sports team participation was positively associated with PA and negatively associated with television viewing and BMI, in a dose-response manner. Compared with Whites, African-Americans reported less PA and more television viewing, and had greater BMI scores. Whereas PA intervention programs that incorporate a sports-team component could benefit all girls, African-American girls could be specifically targeted because of their lower physical activity.
\end{abstract}

Physical inactivity in children and adolescents is a major public health concern because of its association with the prevalence of overweight in young people (23) and the possible impact on other health parameters $(5,8,9,20)$. Compared with boys, girls' physical activity tends to be lower and is characterized by a more marked agerelated decline beginning in early adolescence (7). In addition, African-American youth, especially girls, tend to report less moderate-to-vigorous physical activity (MVPA) and more time in sedentary activities like television viewing (7).

School- and community-based sports teams offer an organized and supervised opportunity for performing physical activity, which might help children, and girls in particular, meet physical activity recommendations $(10,20)$. The 2005 Youth Risk Behavior Surveillance Survey (7) indicated that 50\% of high school girls participated in at least one school- or community-based sports team during the previous year and there was a $27 \%$ age-related decline in participation from ninth $(56 \%)$ to twelfth grade $(41 \% ; 7)$. In addition, $53.9 \%$ of White girls participated on at least one sports team compared with $43.6 \%$ for African-American girls (7). For 12- to 14-year-old girls, it is estimated that the majority (64.6\%) of their MVPA is

\footnotetext{
Sirard is with the Division of Epidemiology and Community Health School of Public Health University of Minnesota Minneapolis, MN 55454-1015. Pfeiffer is with the Dept. of Kinesiology, Michigan State University, East Lansing, MI 48824-1049. Dowda and Pate are with the Dept. of Exercise Science, University of South Carolina, Columbia, SC 29208.
} 
accumulated during organized youth sports (12). Documenting the potential health benefits of sports participation in girls, particularly African-American girls, might help policy makers and community organizers to develop more and better school and community-based sports programs and other physical activity opportunities for all adolescent girls.

Few studies $(3,11,16)$ have addressed the association between sports participation and physical activity, fitness, and body mass index (BMI) in adolescent girls even though the age-related declines in physical activity and sports team participation are greater for girls than boys (7). Even less information is available with regard to how sports participation may affect Caucasian and African-American girls differently on physical activity, fitness, and BMI (6). Because girls and African Americans are both likely to be less active and participate on fewer sports teams than boys and Whites, adolescent African-American girls represent a subpopulation that is at an increased level of risk for becoming inactive. With the exception of one Finnish study (21), sports participation has traditionally been dichotomized as nonparticipants or at least one team during the previous year. Combining all sports team participants into one group might mask potential dose-response relationships because there can be different levels of involvement on sports teams. Therefore, the purpose of this study was to identify racial differences in physical activity, aerobic fitness, and BMI in eighth grade girls stratified by sports-team participation status.

\section{Methods}

\section{Design}

A cross-sectional study design was used to identify the associations between sports team participation and physical activity, fitness and BMI in a sample of eighth grade girls. Baseline data from a school-based, randomized controlled trial to increase physical activity in ninth grade girls were used (18). Data were collected by trained research assistants during the spring of the girls'eighth grade year.

\section{Participants}

Participants were recruited, via in-school assemblies and classroom visits, to participate in a ninth-grade high-school-based intervention to promote physical activity. Baseline measures were collected before school-level randomization as an intervention or control school. The sample presented here represents two cohorts of eighth-grade girls $(n=2,740)$ from 31 South Carolina middle schools during the spring of 1998 and 1999. Because of missing data for key variables, the sample used for analyses included 1,903 participants. Compared with participants that were dropped from the analysis because of partially missing data $(n=837)$, the analysis sample was younger $(13.7 \pm 0.68$ vs. $13.6 \pm 0.63 \mathrm{y} ; p<.001)$, taller $(111.1 \pm 48.96$ vs. $135.6 \pm 44.10 \mathrm{~cm} ; p<.001)$ and weighed less $(98.0 \pm 46.30$ vs. $78.8 \pm 38.15 \mathrm{~kg} ; p<.001)$ although the groups had equivalent BMI scores $(23.4$ \pm 5.67 vs. $23.0 \pm 5.35 ; p=.180$ ). There were similar percentages of sports team participants in the group dropped from the analysis (54\%) and those retained for analysis $\left(58 \%, \chi^{2}=3.13 ; p=.08\right)$. This study was approved by the University of 
South Carolina's Institutional Review Board. The child and their parent or legal guardian provided assent and consent respectively and students were free to withdraw from the study at any time.

\section{Measures}

Three-Day Physical Activity Recall (3DPAR). The 3DPAR self-report instrument (17) was used to assess the physical activity behavior during the previous 3 days, recalling the most proximal day first. Trained data collectors read a prepared script to the students that explained the survey and provided examples of how the girls were to complete the 3DPAR. For this study, all students completed the 3DPAR on a Wednesday. A list of 55 common activities were grouped by the following categories; sleep or bathing, eating, work, after-school/spare-time/hobbies, transportation, and physical activities/sports. The student entered the main activity in which he or she participated during each 30-min time block between the hours of 7:00 a.m. and midnight. In addition, for each time block, the student rated the intensity of the reported activity as light, moderate, hard, or very hard. The intensity categories were verbally described and graphically presented as visual cues. The following description was read to the students, "Light activities require little or no movement with slow breathing, moderate activities require some movement and normal breathing, hard activities require a moderate amount of movement and increased breathing and very hard activities require quick movements and hard breathing."

Questionnaire. Participants also completed a questionnaire that included two items assessing the number of school-based and out-of-school sports teams on which they had participated during the past year (7). The girl's self-reported age (in years) and race were also obtained by this questionnaire.

Aerobic Fitness. Aerobic fitness was estimated by using a modified version of the Physical Work Capacity 170 (PWC170) field test (2). Research assistants followed a written protocol designed to elicit heart rates of 120,150, and 170 beats per minute (bpm) at the end of each 2-min stage (six minutes total; 4,14). Students with a heart rate lower than $160 \mathrm{bpm}$ at the end of the third stage performed a fourth stage to meet this criterion. Each student was fitted with a Polar heart rate monitor (Polar USA, Inc., Lake Success, NY) used to assess her heart rate during the final $10 \mathrm{~s}$ of each stage. For all participants, a common resistance $(0.5 \mathrm{Kp})$ was used for the first stage. Handlebars were fixed at a slight angle toward the subject, knee joint angle at the bottom of the pedal rotation was approximately $15^{\circ}$ and a metronome was used to maintain pedal cadence at $60 \mathrm{rpm}$ (55-65 rpm was considered an acceptable range). The linear association between workload and heart rate was confirmed by calculating the $R^{2}$ and only including tests with an $R^{2} \geq 0.90$. Heart rate responses were extrapolated or interpolated to the workload eliciting $170 \mathrm{bpm}$ and are reported in absolute terms $\left(\mathrm{kg} \cdot \mathrm{m} \cdot \mathrm{min}^{-1}\right)$ and relative to body weight $\left(\mathrm{kg} \cdot \mathrm{m} \cdot \mathrm{min}^{-1} \cdot \mathrm{kg}\right.$ body weight $\left.{ }^{-1}\right)$.

Body Mass Index (BMI). Height and weight (BeFour, Inc. Model PS6600; Saukville, WI) were measured by trained staff to the nearest $1.0 \mathrm{~cm}$ and to the nearest $0.1 \mathrm{~kg}$, respectively, with students dressed in light, indoor clothing. Body mass index was calculated as body mass in kilograms divided by height in meters squared $\left(\mathrm{kg} / \mathrm{m}^{2}\right)$. 


\section{Procedures}

Each participant was scheduled for two data collection visits within 2 weeks of each other. To avoid having students recall their participation in the data collection procedures, the 3DPAR was always administered on the first visit. Height, weight, and demographic information were also collected during the first visit on as many students as time allowed; the remainder had these measures completed on the second visit. All students completed the PWC170 test during the second visit.

\section{Data Reduction}

Responses from both sports team participation questions were summed and students were categorized as no sports team (NonSport), one sports team (OneSport), or more than one sports team (MultiSport) reported during the previous year. The number of 3DPAR time blocks corresponding to vigorous physical activity (VPA; "hard" and "very hard" classifications from the 3DPAR) and moderate-to-vigorous physical activity (MVPA; "moderate", "hard" and "very hard" classifications from the 3DPAR) were averaged across all 3 days. The number of time blocks for watching television and selected sedentary activities (SED; television viewing, computer/video game playing, surfing the Internet, and talking on the phone) were also averaged across the three days. The 3DPAR responses were also used to identify girls meeting a physical activity recommendation (20). Operational definitions were applied to the 3DPAR data to approximate 60 min of MVPA per day (two 30-min blocks), 30 min of VPA per day (one 30-min block), and 2 hours of television viewing per day (four 30-min blocks). In addition, girls were classified as at risk for overweight and overweight using the age specific percentiles from the Centers for Disease Control and Prevention growth charts. Girls at or above the 85th percentile were categorized as at risk for overweight and those above the 95th percentile as overweight. Girls who did not indicate a race $(n=2)$ classified as any other race besides White or African American $(n=56)$ and those who reported "other" $(n=42)$ were not included in this analyses because of the small number of individuals.

\section{Statistical Analysis}

One-way analyses of variance (ANOVA) were used to determine if there were differences between NonSport, OneSport, and MultiSport for age, height, weight and BMI. Because of nonnormal distributions for most of the physical activity variables, Spearman correlations were calculated among sports team participation

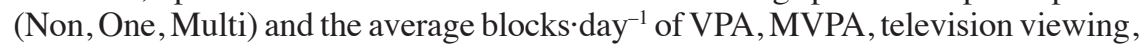
SED, PWC170 results (absolute and relative to body mass) and BMI. Two-way mixed-model ANOVA, controlling for school, were calculated to identify race and sports team participation differences in activity variables (VPA, MVPA, television viewing, SED), aerobic fitness, BMI values, and differences in the proportion of girls meeting physical activity and BMI recommendations.

\section{Results}

Participant characteristics are presented in Table 1. The majority of girls (60\%) reported participating on at least one sports team during the previous year. The 
percentage of White girls participating on at least one sports team was $12 \%$ greater than for the African Americans $(p<.05)$. Across sports team participation categories, African American girls were taller, weighed more and had greater BMI scores than the White girls $(p \leq .05)$.

Spearman correlations between sports team participation and physical activity, fitness and BMI are reported in Table 2, separately by race. Most correlations are statistically significant, although mostly low in magnitude. Across races, sports team participation was associated $(r=.21-.25)$ with average blocks $\cdot d a y^{-1}$ of VPA and MVPA. Although statistically significant and in the expected direction, correlations between sports team participation and blocks day $^{-1}$ of sedentary activity, television viewing, and aerobic fitness for the African American girls were negligible. In contrast, sports team participation was positively associated with aerobic fitness for the White girls ( $r=.22$ and .23 for absolute and weight relative fitness).

The results from the ANOVA models are presented in Figure 1 for the physical activity variables and in Table 3 for aerobic fitness and BMI. The main effect for sports participation indicates that for VPA, MVPA, TV and absolute fitness, all groups were significantly different from each other in a dose-response fashion. The MultiSport girls reported the greatest number of VPA and MVPA blocks'day ${ }^{-1}$, the fewest TV viewing blocks $\cdot$ day $^{-1}$ and had the greatest absolute fitness values. Both the OneSport and MultiSport girls, compared with the NonSport girls, reported fewer SED activity blocks $\cdot$ day $^{-1}$, had greater weight relative fitness, and lower BMI values. Significant race main effects were also detected for all of the variables except weight relative aerobic fitness. White girls, compared with African American, reported more blocks $\cdot$ day $^{-1}$ of VPA and MVPA, fewer blocks $\cdot$ day $^{-1}$ of TV and SED and had lower BMI values (all comparisons $p<.001$ ). There were no significant sports team participation by race interactions.

The percent of students meeting physical activity recommendations and BMI standards are presented in Table 4. Across race groups, sports team participation groups were all significantly different from each other in a dose-response fashion. MultiSport girls were the most likely to meet VPA, MVPA, and TV recommendations; NonSport girls were the least likely to meet these recommendations $(p \leq .01$ all comparisons). For the BMI standards, across race groups, both OneSport and MultiSport girls were less likely to be at risk for overweight and overweight ( $p \leq$ .04 ), compared with the NonSport girls. Across sports team participation groups, White girls were more likely to meet physical activity, television, and BMI recommendations, compared with the African-American girls $(p \leq .01)$.

\section{Discussion}

The purpose of this study was to identify racial differences in physical activity, aerobic fitness, and BMI in eighth-grade girls categorized by sports team participation status (Non, One, and MultiSport). The main findings from this study were that sports team participation was associated with greater reported vigorous and moderate-to-vigorous physical activity, and less television viewing in a dose response manner. The absence of significant team sports participation by race interactions indicates that team sports participation was beneficial for all girls in this sample regardless of race. Still, there were significant race main effects indicating that the African-American girls participated in fewer sports teams, had lower 


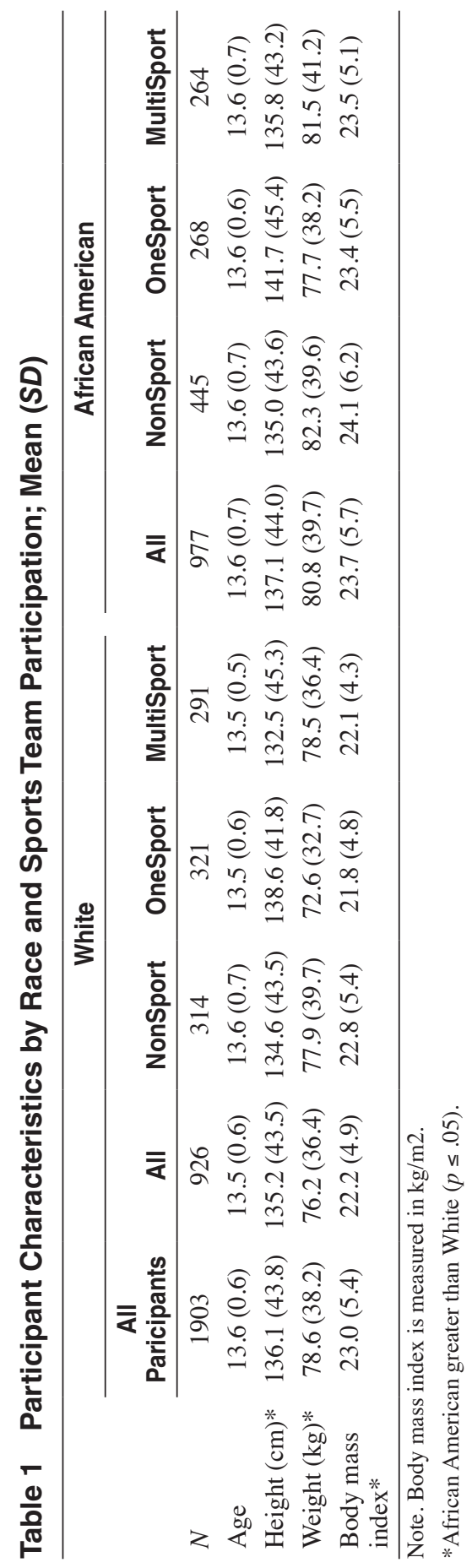




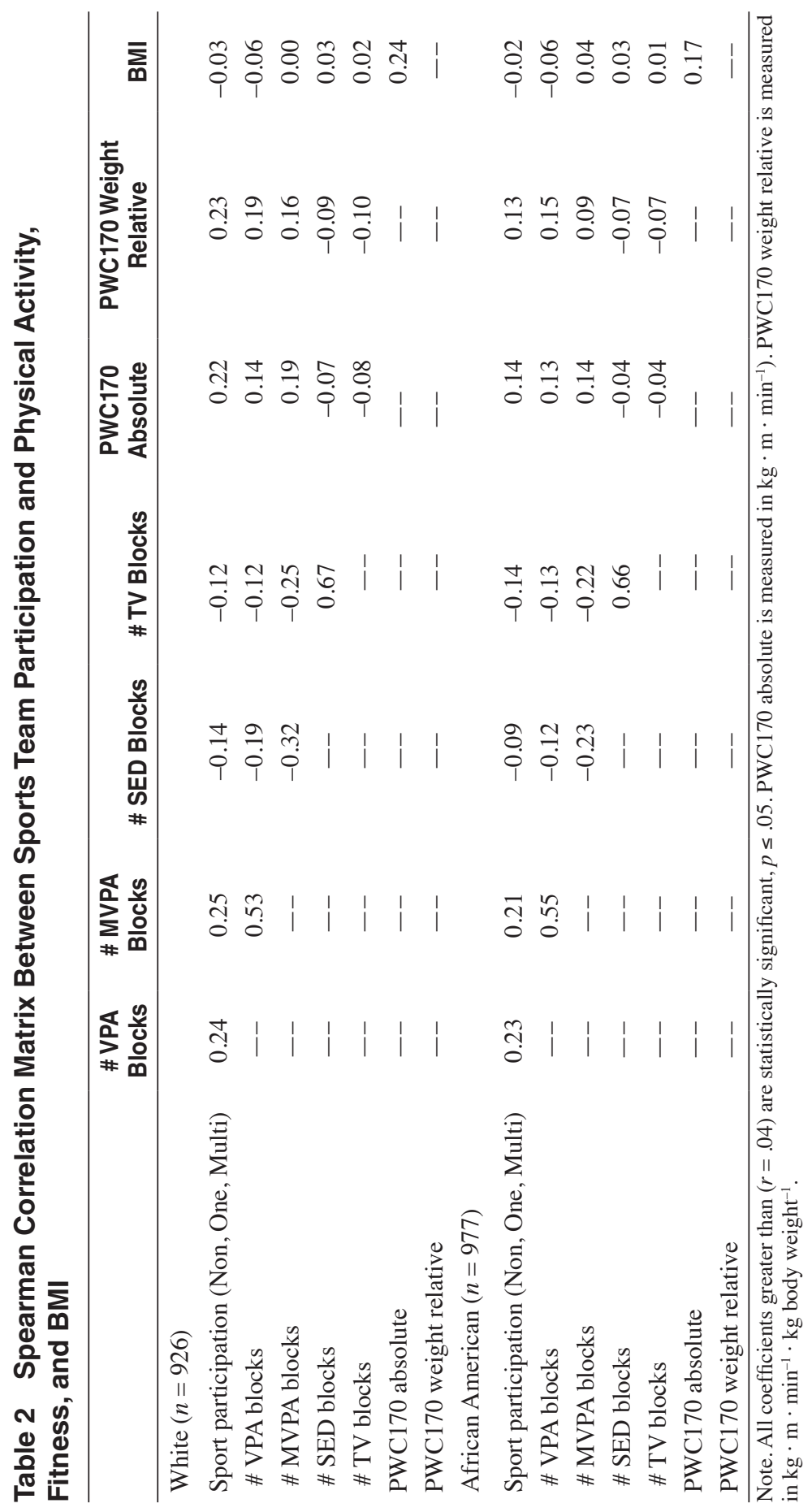



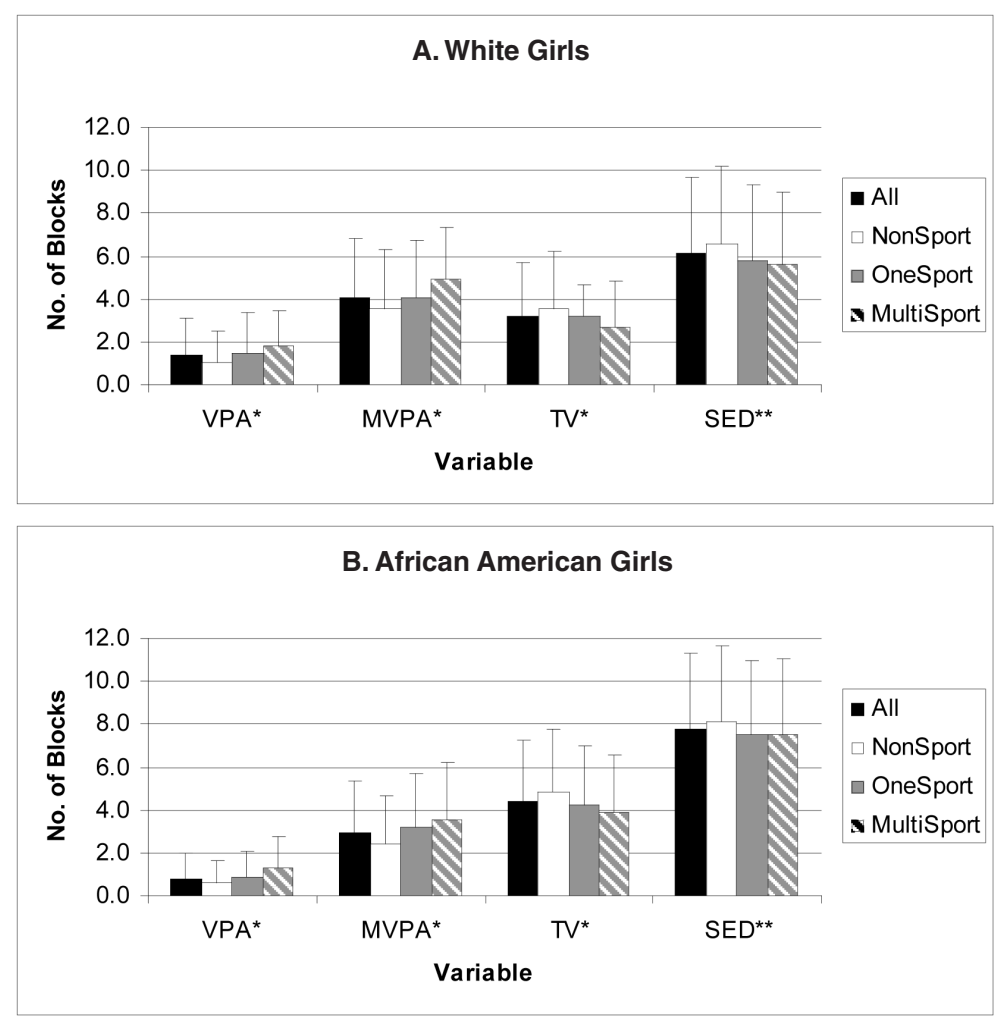

Figure 1 - Number of 3DPAR blocks of vigorous (VPA), moderate-to-vigorous physical activity (MVPA), television viewing (TV), and sedentary activities (SED) for White girls (panel A) and African American Girls (panel B). *Sport Participation main effect (all groups different from each other; $p \leq .012)$ and race main effect $(p<.001)$ for VPA, MVPA, and TV. **Sport Participation main effect (NonSport different from OneSport and MultiSport; $p \leq .023)$ and Race main effect $(p<.001)$ for SED. Sedentary activities (SED) included television viewing, computer or video game playing, surfing the Internet, and talking on the phone.

physical activity and aerobic fitness levels, and more television time and greater BMI values, compared with the White girls. These findings are consistent with and expand on previous research of the effects of sports team participation and physical activity $(12,16)$, fitness $(1,3)$, and BMI $(3,11)$.

Sports team participants reported more blocks of vigorous and moderate-tovigorous physical activity and fewer blocks of sedentary activity compared with nonparticipants. In a nationally representative sample of high school boys and girls (16), sports team participation was also associated with a higher level of physical activity. Approximately $60 \%$ of the "high-active" students participated on at least one sports team during the previous year while only $22 \%$ of the "low-active" students reported sports team participation (16). Our results also are consistent 


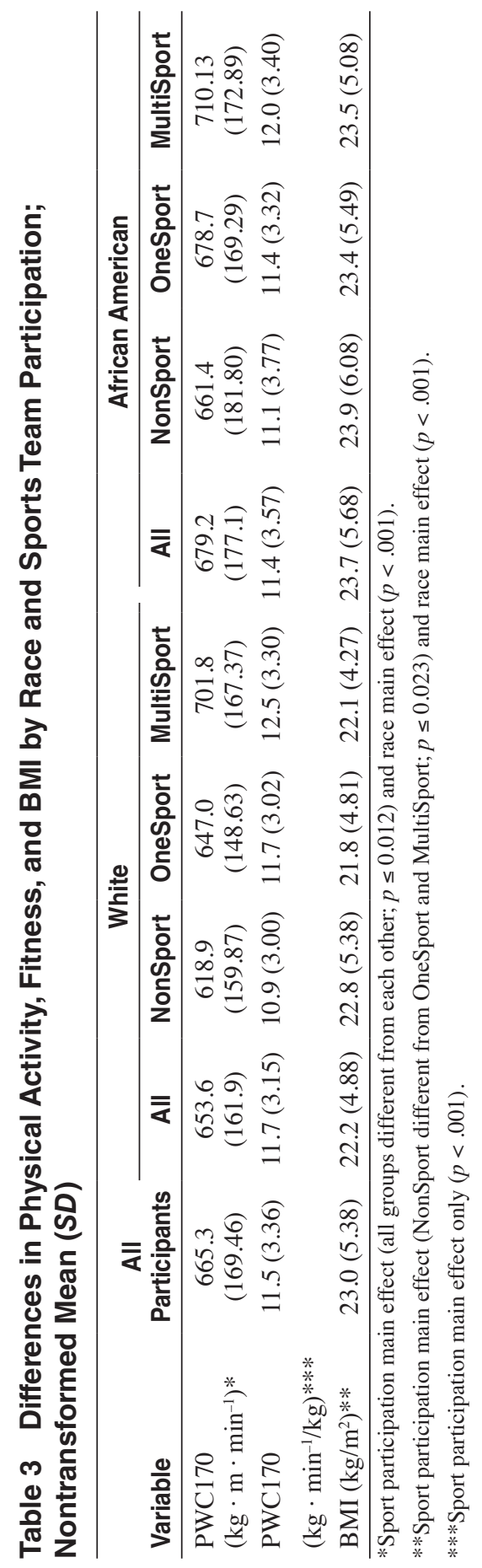




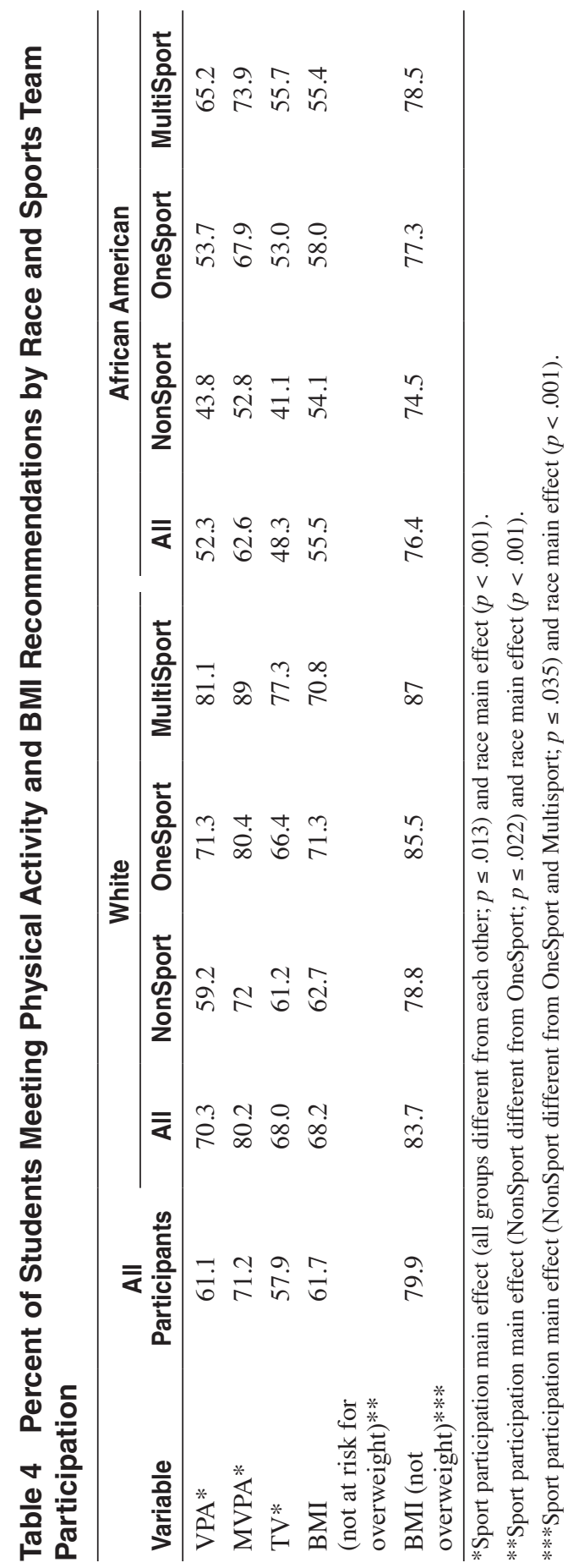


with previous research indicating that female middle school sports participants ( $\geq 1$ sports team) spend less time watching television than their nonparticipating peers (12). The data presented here extend these previous findings by identifying a dose-response relationship between sports team participation and physical activity and television viewing time.

In addition, several European studies have observed that, compared with youth physical activity, youth sports participation is a stronger predictor of young adult physical activity. In particular, the Cardiovascular Risk in Young Finns Study (22) indicates that, compared with their measure of physical activity, sports-team participation had slightly higher associations with physical activity at 9 and 12 years following baseline. In the Amsterdam Growth and Health Study (24), it was observed that the primary decrease in physical activity was because of nonorganized sporting activity while "other" activity and organized sporting activity remained relatively stable from 13 to 27 years of age. Using a longitudinal design, Tammelin et al. (21) reported greater odds of 31 year old Finnish women being active or very active if, when they were 14 years old, they reported sports activities at least once a week and at least 2-3 times a week, respectively. Cultural differences in the availability of adult sports club teams, however, makes comparisons to U.S. populations difficult. Although these European studies are longitudinal, the data presented in this paper was cross-sectional. Therefore, any association between these middle school girls' sports participation and later physical activity is unknown.

Sports team participants had higher levels of absolute fitness in a dose response manner as measured by the PWC170 submaximal bicycle test. When fitness was expressed relative to body mass, results were similar to previous research showing a positive association between sports participation and aerobic fitness $(1,3)$ and further supports the association of organized sports programs with adolescent physical activity and fitness. Compared with White girls, African-American girls had higher fitness scores when measured in absolute terms $\left(\mathrm{kg} \cdot \mathrm{m} \cdot \mathrm{min}^{-1}\right)$ but similar relative fitness scores $\left(\mathrm{kg} \cdot \mathrm{m} \cdot \mathrm{min}^{-1} \cdot \mathrm{kg}\right.$ body weight $\left.{ }^{-1}\right)$. The higher BMI values for the African-American girls might be responsible for their greater absolute fitness which, in turn, may reflect a greater fat-free mass because additional fat mass would not be expected to result in greater levels of fitness.

White race and participating on at least one sports team were associated with lower BMI values compared with African American and nonparticipants, respectively. Using NHANES III data, Dowda et al. (11) observed that 14- to 16year-old female sports team participants were less likely to be classified as overweight. Similarly, a study including 15 year old Irish girls (3) observed a negative association between a sports participation score and percent body fat calculated from four skinfold sites. In contrast, two smaller studies including high school (1) and middle school (12) girls observed no difference in BMI between sports team participants and nonparticipants. The current study extends the previous findings of an inverse association between sports participation and BMI by incorporating three categories of sports team participation.

Despite participation on two or more sports teams, African-American multisport participants had higher BMI values (23.5) compared with their White counterparts $(\mathrm{BMI}=22.1)$. Previous work has documented a cultural difference in body size perceptions with African-American females being more comfortable with and accepting of a larger body size $(13,15,19)$. With such a belief system, overweight 
African American girls might be less intimidated about playing sports, compared with overweight White girls. Additionally, African American girls might preferentially participate in sports where a larger body size is an advantage (basketball) as opposed to gymnastics or long-distance running.

The cross-sectional nature of these data prevents us from addressing causality between sports participation and physical activity, fitness, and weight status. Future prospective studies are needed to assess the effect of sports team participation on these and other health outcomes in U.S. children and adolescents. The use of self-report to measure physical activity might be seen as a limitation since the use of accelerometers overcomes possible recall errors by objectively measuring body movement. For this large study of adolescent girls from geographically diverse areas across the state of South Carolina, the use of self-reports provided a lower cost and less intrusive means of capturing physical activity behavior, however. In addition, the 3DPAR has been validated in this age group (17) using the ActiGraph accelerometer as the criterion method. One limitation of the 3DPAR is that it does not discriminate between organized and free-play sports (e.g., basketball team game or practice vs. shooting baskets as leisure time activity). Therefore, we were unable to calculate the percent of physical activity obtained from organized sports team participation.

In conclusion, participation on a greater number of sports teams in these eighth-grade girls was associated with greater amounts of physical activity, and aerobic fitness, and less television watching, sedentary activity, and lower BMI values. The categorization of sports team participation as Non, One, and Multiteam participants provided evidence of a positive dose-response relationship between sports team participation and physical activity and a negative association with television viewing. Sports-team participation was associated with physical activity, fitness, and BMI similarly for White and African American girls. Because the African-American girls were less active and watched more television, however, the African-American girls might require targeted and culturally relevant sports and physical activity programs designed to increase physical activity and prevent or treat excess weight.

\section{Acknowledgments}

This research was supported by NHLBI 1RO1 HL57775. Dr. Sirard was supported by Public Health Service NRSA No. 5 T32 HL 07034 from the National Heart, Lung, and Blood Institute.

\section{References}

1. Beets, M.W., and K.H. Pitetti. Contribution of physical education and sport to healthrelated fitness in high school students. J. Sch. Health. 75:25-30, 2005.

2. Bengtsson, E. The working capacity in normal children, evaluated by submaximal exercise on the bicycle ergometer and compared with adults. Acta Med. Scand. 154:91-109, 1955.

3. Boreham, C.A., J. Twisk, M.J. Savage, G.W. Cran, and J.J. Strain. Physical activity, sports participation, and risk factors in adolescents. Med. Sci. Sports Exerc. 29:788-793, 1997.

4. Boreham, C.A.G., V.J. Paliczka, and A.K. Nichols. A comparison of the PWC170 and 20-MST tests of aerobic fitness in adolescent schoolchildren. J. Sports Med. Phys. Fitness. 30:19-23, 1990. 
5. Bradney, M., G. Pearce, G. Naughton, et al. Moderate exercise during growth in prepubertal boys: changes in bone mass, size, volumetric density and bone strength. A controlled prospective study. J. Bone Miner. Res. 13:1814-1821, 1998.

6. Bungum, T.L., and M.L. Vincent. Determinants of physical activity among female athletes. Am. J. Prev. Med. 13:115-122, 1997.

7. Centers for Disease Control and Prevention. Youth risk behavior surveillance - United States, 2005. MMWR Morb. Mortal. Wkly. Rep. 55:1-112, 2006.

8. Chen, W., W. Bao, S. Begum, A. Elkasabany, S.R. Srinivasan, and G.S. Berenson. Agerelated patterns of the clustering of cardiovascular risk variables of syndrome $\mathrm{X}$ from childhood to young adulthood in a population made up of black and white subjects: the Bogalusa Heart Study. Diabetes. 49:1042-1048, 2000.

9. Committee on Nutrition. Prevention of Pediatric Overweight and Obesity. Pediatrics. 112:424-430, 2003.

10. Committee on Sports Medicine and Fitness and Committee on School Health. Organized sports for children and preadolescents. Pediatrics. 107:1459-1462, 2001.

11. Dowda, M., B.E. Ainsworth, C.L. Addy, R. Saunders, and W. Riner. Environmental influences, physical activity, and weight status in 8- to 16-year-olds. Arch. Pediatr. Adolesc. Med. 155:711-717, 2001.

12. Katzmarzyk, P.T., R.M. Malina, T.M. Song, and C. Bouchard. Physical activity and health-related fitness in youth: a multivariate analysis. Med. Sci. Sports Exerc. 30:709-714, 1998

13. Kelly, A.M.W.M., M.E. Eisenberg, M. Story, and D.N. Neumark-Sztainer. Adolescent girls with high body satisfaction: who are they and what can they teach us? J. Adolesc. Health. 37:391-396, 2005.

14. Mahoney, C. 20-MST and PWC170 validity in non-Caucasian children in the UK. BMJ. 26:45-47, 1992.

15. Nishina, A., N.Y. Ammon, A.D. Bellmore, and S. Graham. Body dissatisfaction and physical development among ethnic minority adolescents. J. Youth Adolesc. 35:179-191, 2006.

16. Pate, R.R., G.W. Heath, M. Dowda, and S.G. Trost. Associations between physical activity and other health behaviors in a representative sample of US adolescents. Am. J. Public Health. 86:1577-1581, 1996.

17. Pate, R.R., R. Ross, M. Dowda, S.G. Trost, and J.R. Sirard. Validation of a 3-day physical activity recall instrument in female youth. Pediatr. Exerc. Sci. 15:257-265, 2003.

18. Pate, R.R., D.S. Ward, R.P. Saunders, G. Felton, R.K. Dishman, and M. Dowda. Promotion of physical activity among high-school girls: A randomized controlled trial. Am. J. Public Health. 95:1582-1587, 2005.

19. Rucker, C.E., III and T.F. Cash. Body images, body size perceptions, and eating behaviors among African-American and White college women. Int.J.Epidemiol. 12:291-299, 1992.

20. Strong, W.B., R.M. Malina, C.J.R. Blimkie, et al. Evidence based physical activity for school-age youth. J. Pediatr. 146:732-737, 2005.

21. Tammelin, T., S. Nayha, A.P. Hills, and M.R. Jarvelin. Adolescent participation in sports and adult physical activity. Am. J. Prev. Med. 24:22-28, 2003.

22. Telama, R., X. Yang, L. Laakso, and J. Viikari. Physical activity in childhood and adolescence as predictor of physical activity in young adulthood. Am. J. Prev. Med. 13:317-323, 1997.

23. U.S. Department of Health and Human Services. Healthy People 2000: National Health and Disease Prevention Objectives. Washington, DC: U.S. Dept. of Health and Human Services, 1991, pp. 91-125.

24. Van Mechelen, W., J.W. Twisk, G.B. Post, J. Snel, and H.C. Kemper. Physical activity of young people: the Amsterdam Longitudinal Growth and Health Study. Med. Sci. Sports Exerc. 32:1610-1616, 2000. 